\title{
The recovery through welding of the geometric shape on passenger railcars friction liner
}

\author{
Carmen (Popișteanu) Petrescu ${ }^{1}$, Gheorghe Solomon ${ }^{2}$, Dumitru Titi Cicic ${ }^{2}$, Oana \\ Roxana Chivu' ${ }^{2}$ and Corneliu Rontescu ${ }^{2}$ \\ ${ }^{1}$ Autoritatea Feroviară Română (AFER), Bucuresti, Romania \\ ${ }^{2}$ Facultatea de Inginerie Industriala și Roboți, Ingineria calitatii si tehnologii industriale, \\ Universitatea Politehnica Bucuresti, Romania \\ E-mail: popisteanu.carmen@gmail.com
}

\begin{abstract}
Friction liner (FL) is a component of the brake carriage equipment for passenger railcars, included in risk class 1A, according to OMT 290/2000, with a normal service life of minimum 10 years (this does not take into account possible accidents or damage caused by the failure of other elements). According to the documentation, the friction linings (FL)s are checked every six months, and if any malfunctions that may endanger the proper functioning are found, the friction linings (FL)s are subjected to repair by replacing with new spare parts from the manufacturer, from import, which entails significant costs, either by technological operations of repair / reconditioning for reuse under maximum safety conditions. This paper presents a series of qualitative and quantitative results, by means of tables / graphs, obtained as a result of applying the technology of recovering the geometric shape (after wear in operation) using the Shielded Metal Arc Welding process (SMAW) [1], as a way of avoiding imports.
\end{abstract}

Keywords: welding reconditioning, railways industry, friction liner, deformations

\section{Introduction}

Due to the modernization of both rolling stock and railway infrastructure, train travel speeds currently exceed $120 \mathrm{~km} / \mathrm{h}$. At these speeds, the braking power of the brake shoes is exceeded[2]., and in these conditions, it is passed to the disc brake [3] -[4] (Figure 1) which provides the braking power at high speeds, having at the same time additional advantages such as low cost maintenance and passengers comfort at the time of braking [5].

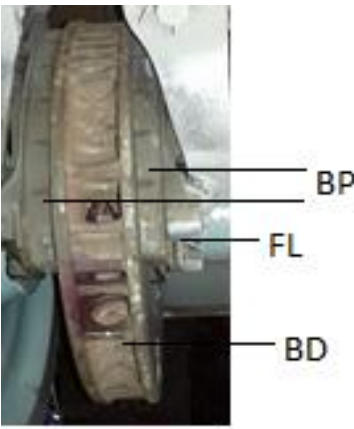

a) Frontal view

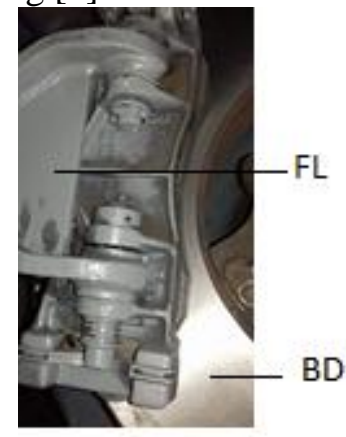

b) Lateral view

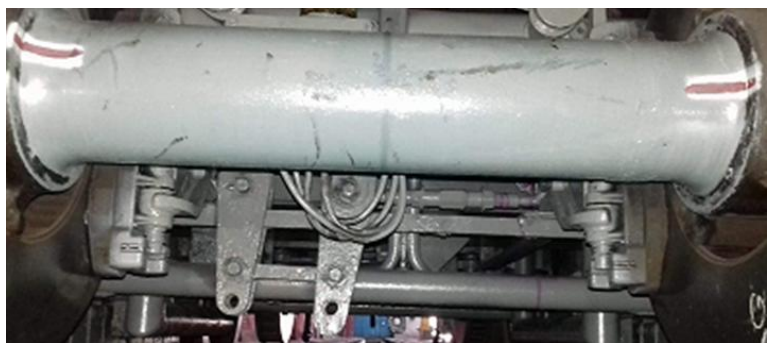

c) General view

Figure 1. Example of disc brakes (FL-friction liner, BD brake disc, BP-brake pad) 
The grip of the brake pad(BP) in the friction liner(FL) is shown in Figure 2.

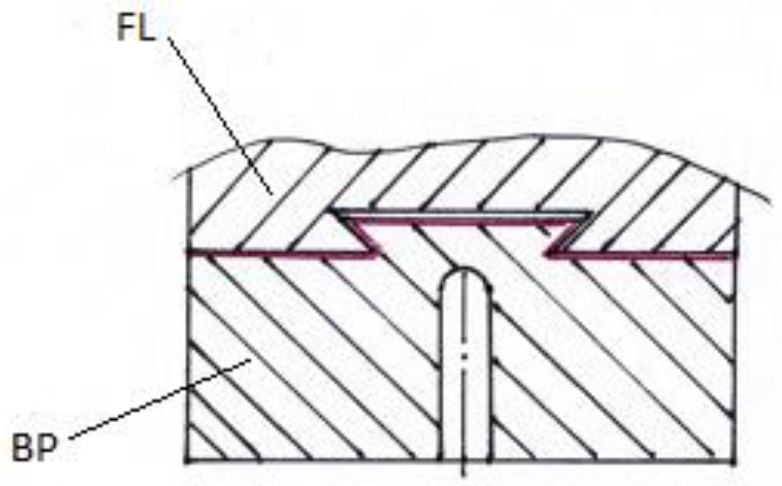

Figure 2. BP-FL assembly, „swallow tail” catch

BP-FL clamping is achieved through a "swallow tail" profile. Due to the high friction forces that occur during braking, the FL is worn out over time, endangering the proper functioning of the entire assembly and consequently, the possibilities of braking under maximum safety conditions.

Once every minimum 6 months (according to table 3.3 of Annex I, Ordinance no. 1359/2012) the FLs are checked during the railcars' periodic review. If the degree of wear no longer ensures the fixed grip of the brake pads, they are dismantled and subjected to further examinations. Then the decision is taken to repair or reject the product. The area that endangers the good functioning is the flank of the swallow tail profile, as its wear leads to the detachment of the brake pad, and therefore, the braking function is no longer ensured.

\section{Constructive form restoration possibilities and wear correction}

According to specialized literature, one of the technological process of recovering the constructive form is welding [6], which in Romania means using mainly manual welding with coated electrode (SMAW).

Although the piece is made of cast iron (cast iron with nodular graphite EN-GJS-400-15C) considered to have low weldability due to its high carbon content [7], cast iron welding is increasingly widespread for repair operations such as wear.

The steps required to restore friction liner constructive and dimensional form are:

- milling (Figure 3a)

- material deposition by welding (Figure 3b)

- optical/visual examination and with penetrating liquids

- final milling

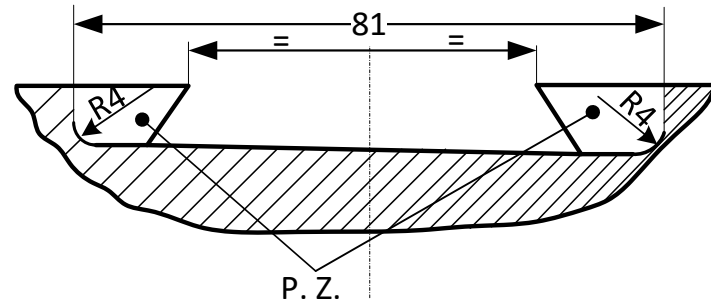

a) mechanical processing elimination of ,swallow tail" profile (P.Z. - the zone to be removed)

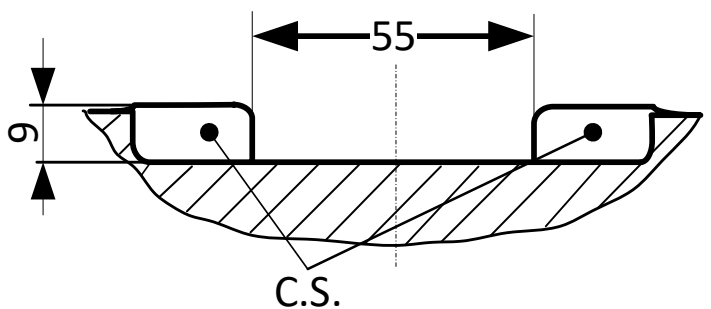

b) material deposit by welding (C.S. - deposit material)

Figure 3. Stages and dimensions of FL welding repair 
Thoth Publishing House

\section{Materials used}

\subsection{Basic material}

According to the designer of the brake liner, the basic material used to produce the product analysed in the work is a cast iron with nodular graphite EN-GJS-400-15C.

This cast iron mark is symbolized, in different standards, according to table 1:

Table 1. Coding according to various standards [11]

\begin{tabular}{|l|l|l|}
\hline Item & Standard & Code \\
\hline 1 & EN 1563 SYM (EU) & EN-GJS-400-15C \\
\hline 2 & EN 1563 NR (EU) & EN-JS1030 \\
\hline 3 & DIN 1693 (DE) & GGG40 \\
\hline 4 & WERKSTOFFNUMMER (DE) & 0.7040 \\
\hline 5 & ASTM A536-584 (US) & $60 / 40 / 52$ \\
\hline 6 & ALT & GGG 40, GGG-40 \\
\hline
\end{tabular}

According to the EN1563Founding - Spheroidalgraphite cast irons standard, the chemical and mechanical characteristics of this cast iron are indicated in table 2, respectively table 3 :

Table 2. Chemical composition of the source EN-GJS-400-15C

\begin{tabular}{|l|l|l|}
\hline Item & Chemical Element & Value [\%] \\
\hline 1 & $\mathrm{C}$ & $3.4-3.85$ \\
\hline 2 & $\mathrm{Si}$ & $2.3-3.1$ \\
\hline 3 & $\mathrm{Mn}$ & $0.1-0.3$ \\
\hline 4 & $\mathrm{~S}$ & Max.0.02 \\
\hline 5 & $\mathrm{P}$ & max.0.10 \\
\hline 6 & $\mathrm{Fe}$ & Remaining amount up to $100 \%$ \\
\hline
\end{tabular}

Table 3. Mechanical characteristics of cast iron EN-GJS-400-15C [12]

\begin{tabular}{|c|c|c|c|c|c|c|}
\hline Item & Symbol & Number & $\begin{array}{l}\text { Thickness } \\
{[\mathrm{mm}]}\end{array}$ & $\begin{array}{l}\mathrm{R}_{\mathrm{m}}{ }^{*} \\
{\left[\mathrm{~N} / \mathrm{mm}^{2}\right]} \\
\text { min. }\end{array}$ & $\begin{array}{l}\mathrm{Rp}_{0.2}{ }^{* *} \\
{\left[\mathrm{~N} / \mathrm{mm}^{2}\right]} \\
\text { min. }\end{array}$ & $\begin{array}{ll}\text { A } & {[\%]} \\
* * * & \\
\text { Min. } & \\
\end{array}$ \\
\hline 1 & \multirow{3}{*}{$\begin{array}{l}\text { EN-GJS-400- } \\
15 \mathrm{C}\end{array}$} & \multirow[t]{3}{*}{ EN-JS1072 } & $\mathrm{t}<30$ & 400 & 250 & 15 \\
\hline 2 & & & $30<\mathrm{t}<60$ & 390 & 250 & 14 \\
\hline 3 & & & $60<t<200$ & 370 & 240 & 11 \\
\hline
\end{tabular}

* Ultimate Tensile Strength; ** Yield strength; *** Elongation

Cast iron EN-GJS-400-15C also presents the following characteristics:

- Brinell hardness: 135 - 180HB;

- Elasticity modulus: Eo $=169\left[\mathrm{kN} / \mathrm{mm}^{2}\right]$;

- Ferrite content: minimum 85\%;

- Breaking energy at $20^{\circ} \mathrm{C}: 10[\mathrm{~J}]$

\subsection{Addition material}

The electrode used in the experimental part was E C NiFe-1-BG-11, according to EN ISO 1071.This electrode mark is suitable for welding / charging / welding repair of the following types of cast iron: cast iron etc. EN 1561: EN-GJL-100 (GG10) till EN-GJL-350 (GG35), EN 1562: EN-GJMB-350 (GTS 35) till EN-GJMB-550 (GTS 55), EN-GJMW-350 (GTW 35) till EN- GJMW-550 (GTW 55), EN1563: EN-GJS-400 (GGG 40) till EN-GJS-700 (GGG 70). 
According to the manufacturer:

- the material deposited with this electrode presents the following chemical composition: $\mathrm{C}=$ $1.00 \%, \mathrm{Fe}=43 \%$ and the rest $\mathrm{Ni}$

- the breaking limit is $430-470\left(\mathrm{~N} / \mathrm{mm}^{2}\right)$, the flow limit $320-360\left(\mathrm{~N} / \mathrm{mm}^{2}\right)$, the $10 \%$ elongation and the hardness of $160-200 \mathrm{HB}$

- type of current: AC / DC

- positions of use PA (1G), PB (2F) and PC (2G)

The welding technology parameters recommended by the manufacturer are shown in table 4 below:

Table 4. Parameters recommended by the manufacturer

\begin{tabular}{|l|l|l|}
\hline Diameter [mm] & Length $[\mathrm{mm})]$ & Welding current $[\mathrm{A}]$ \\
\hline 2.50 & 300 & $45-80$ \\
\hline 3.25 & 300 & $60-120$ \\
\hline 4.00 & 350 & $90-140$ \\
\hline
\end{tabular}

\section{Experiments performed}

\subsection{Welding techniques}

In order to determine the optimum conditions for the reconditioning by welding, three samples were performed, as follows:

- a freely welded sample (coded FW)

- a welded sample in a special device for deformation reduction (DW coded)

- a welded sample in a special device, which was subsequently subjected to the milling operation in order to obtain the final dimensions of the piece (DWM coding)

\subsubsection{FW welding technique}

In the first stage, the ,swallow tail" profile was removed by mechanical processing resulting an U profile at $90^{\circ}$. (Figure 3a)

The stages required to realize the piece $\mathrm{FW}$ were:

- piece positioning on a $45^{\circ}$ angle over horizontal (represented by the welding rack)

-first cord deposit with the parameters indicated in Table 5,

- slag removed from the first cord

- deposit of the 2-n layers with the parameters indicated in Table 5, until the dimension indicated in the repair technology was reached

- after the welding finished on one flank of the piece, the piece was rotated 180 degrees clockwise to deposit material trough welding on the other flank of the piece in the same manner.

The welding of the rows was continuous, with the beginning of each row from the same part, from left to right, and the cooling of the piece was done on the welding rack, protected from air flow.

\subsubsection{DW sample welding technique}

After realising the U profile at $90^{\circ}$. (Figure.3a).by mechanically removing the „swallow tail” profile, the piece was fastened into a device specially designed to avoid deformations due to the reconditioning by welding (Figure 4 ):

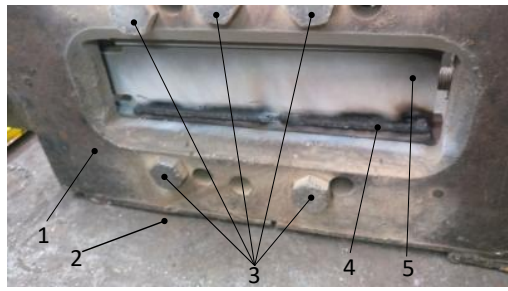

Figure 4. Piece welded in the device 
Thoth Publishing House

1- fastening device; 2-welding rack; 3 - fastening system; 4 -welding cord; 5- friction liner

It is worth mentioning that for a better penetration, the device and the piece were inclined at an angle of $90^{\circ}$ to the horizontal plane[8].

The rules and the parameters of the operation were identical with the ones from FW welded piece.

\subsection{Parameters}

The parameters used in the experiments are indicated in table 5 below:

Table 5. Parameters for welding repair technology

\begin{tabular}{|l|l|l|l|l|l|l|l|l|l|}
\hline \multirow{2}{*}{$\begin{array}{c}\text { Number } \\
\text { of } \\
\text { passings }\end{array}$} & \multirow{2}{*}{$\begin{array}{c}\text { Diammeter } \\
\text { electrod } \\
{[\mathrm{mm}]}\end{array}$} & \multicolumn{2}{|c|}{$\begin{array}{c}\text { Current } \\
\text { intensity [A] }\end{array}$} & \multirow{2}{*}{$\begin{array}{c}\text { Voltage[ } \\
\text { V] }\end{array}$} & $\begin{array}{c}\text { Current } \\
\text { type, } \\
\text { polarity }\end{array}$ & \multicolumn{2}{|c|}{$\begin{array}{c}\text { Welding } \\
\text { speed } \\
{[\mathrm{mm} / \mathrm{min}]}\end{array}$} & \multicolumn{2}{|c|}{$\begin{array}{c}\text { Lineal energy } \\
{[\mathrm{J} / \mathrm{mm}]}\end{array}$} \\
\cline { 9 - 12 } & Min. & Max. & & & & Min. & Max. & Min. & Max. \\
\hline 1 & 2,5 & 90 & 110 & 19 & $\mathrm{DC}^{-}$ & 120 & 160 & 684 & 627 \\
\hline $2 \ldots \mathrm{n}$ & 3,25 & 115 & 120 & 21 & $\mathrm{DC}^{-}$ & 150 & 180 & 772.8 & 672 \\
\hline
\end{tabular}

\section{Results and conclusions}

\subsection{Results obtained}

The samples shown in Figure 5 below resulted from the experiment:

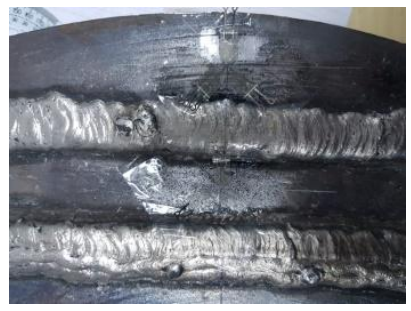

a) Sample FW

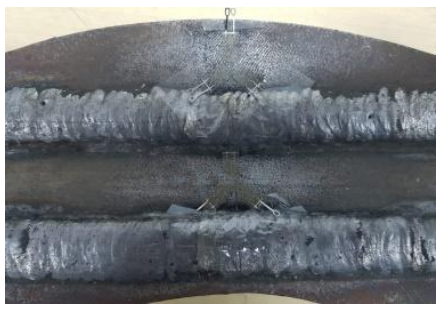

b) Sample DW

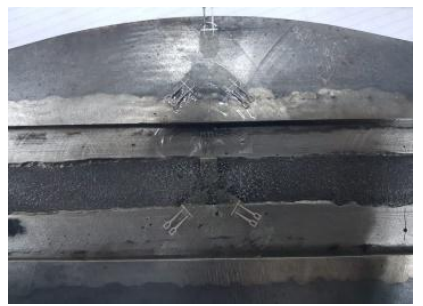

c) Sample DWM

Figure 5. Reconditioned friction linings

The resulting samples were subjected to penetrant liquid (LP) examination, Figure 6 below:

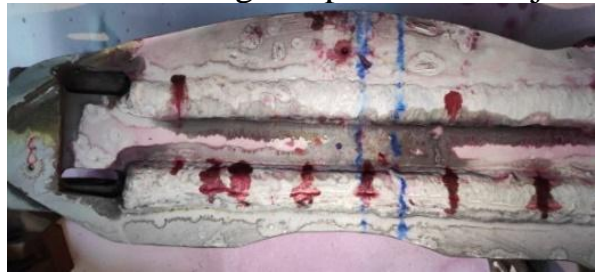

a) Sample FW

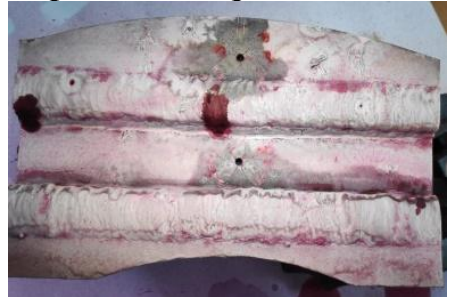

b) Sample DW

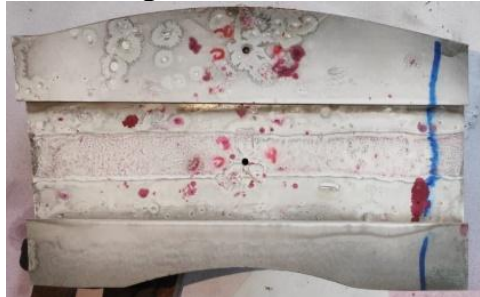

c) Sample DWM

Figure 6. Examination of the samples with penetrating liquids

From the examination with penetrating liquids, Figure 6 above, it can be observed that:

- in the case of the freely welded sample, a large number of transverse cracks on the cord and a smaller number of pores were highlighted

- in the case of the device welded sample, two transverse cracks and a relatively large number of pores were highlighted

- in the case of the device welded sample and subsequently milled, when examined with LP, a single crack was revealed, but a large number of pores. 
Some aspects regarding the shape and order of the rows for the freely welded sample and for the device welded sample are shown in Figure 7. below:

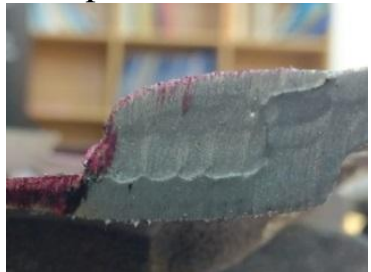

a) Layers - Sample FW

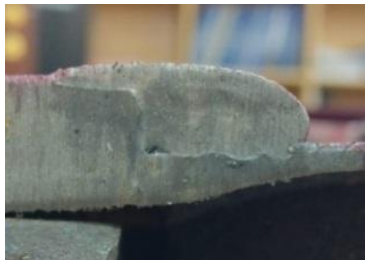

b) Layers - Sample WD

Figure 7. Macroscopic aspects of the samples welded freely and in the device

Analysing Figure 7 above, it can be observed the cords deposited by welding to obtain the necessary height. Also, it is observed that in the area of basic material - cord material, in the case of DW sample, a zone of lack of fusion was highlighted. Because one of the problems arising from the application of any welding technological process is the resulting deformations[9]- [10], and in addition, at the FL repair they must not exceed a certain value, the resulting samples were analysed in order to establish the values of the deformations, with the help of the application ArtCAM. Some images taken during the analysis are shown in Figure 8. In order to differentiate the samples, in the application (ArtCAM) used to measure the deformations, the following colours were assigned:

- the yellow colour represents the horizontal plane of reference for deformations

- the blue colour represents the sample DW

- the green colour represents the sample FW

- the red colour represents the sample DWM

The association of colours with the pieces was made for the contrast with the horizontal plane in order to visualize the deformations.
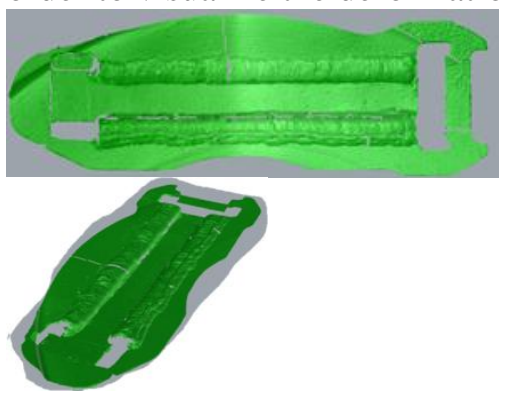

a) Sample welded without constraint - base for measurements
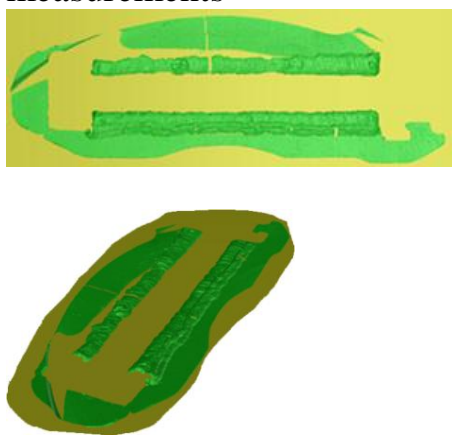

d) Sample welded without constraint - level of deformations

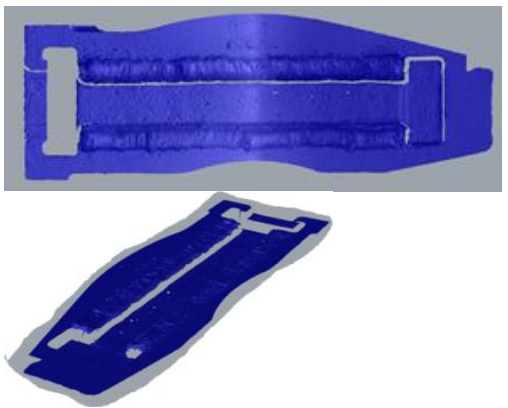

b) Sample welded in devicebase for measurements

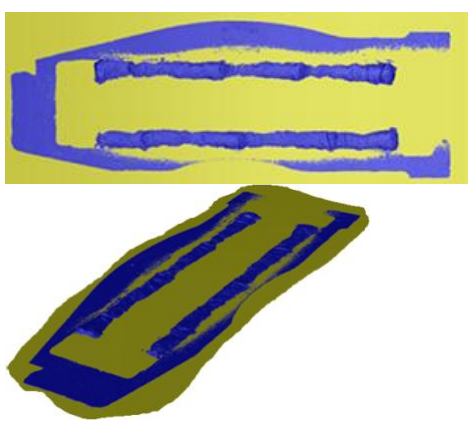

e) Sample welded in device level of deformations

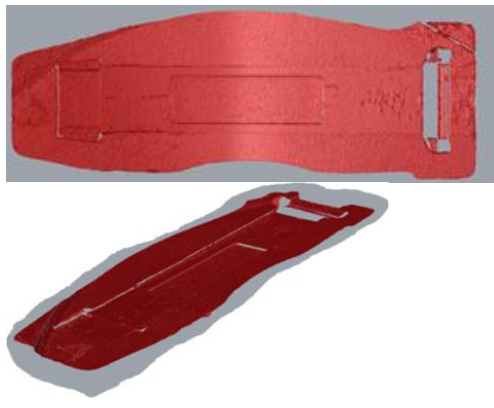

c) Proof sample-unreconditioned

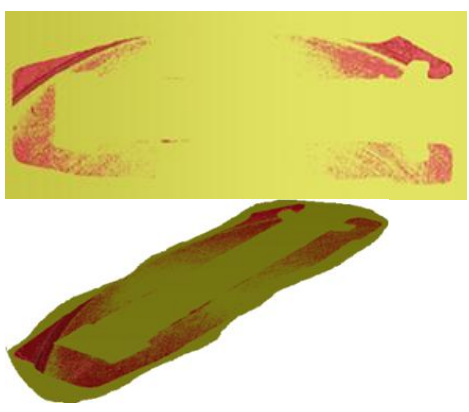

f) Proof sample -unreconditioned

Figure 8. Aspects regarding the deformation level 
The location of measuring points for all samples, complied with Figure 9 indications:

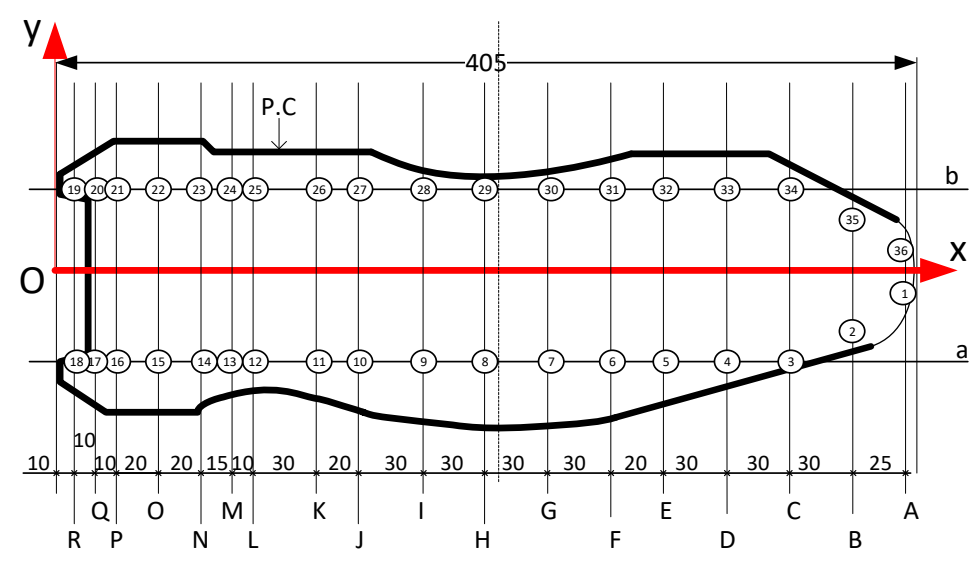

a) Location of deformation measurement points

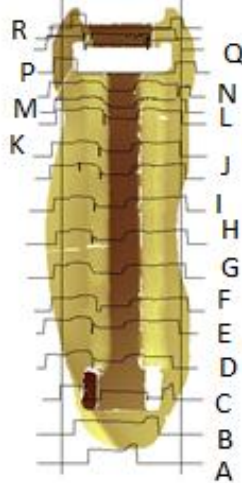

b) Measuring sections - FW piece

Figure 9. Location of deformation measurement points

P.C - sample contour; A ... R - measuring sections; (i) - measuring points ( $1 \ldots 36)$, the unit of measurement of the numerical values is $\mathrm{mm}$, $\mathrm{a}$ and $\mathrm{b}$ are lines of measurement.

Following the use of the IT solution ARTCAM, necessary to determine the values of deformations - the results obtained were presented in Table 6. and in Figures 10-13.

Table 6. Deformation values

\begin{tabular}{|c|c|c|c|}
\hline \multirow{2}{*}{$\begin{array}{c}\text { Measuring } \\
\text { point* }\end{array}$} & \multirow{2}{*}{$\frac{\text { Distance }[\mathrm{mm}]}{\mathrm{x}}$} & \multicolumn{2}{|c|}{ Value $[\mathrm{mm}]^{* * *}$} \\
\hline & & DW sample** & FW sample** \\
\hline 1 & 400 & -0.07 & -0.9 \\
\hline 2 & 375 & -0.09 & -1.4 \\
\hline 3 & 345 & -0.15 & -1.8 \\
\hline 4 & 315 & -0.2 & -2.06 \\
\hline 5 & 285 & -0.26 & -2.28 \\
\hline 6 & 265 & -0.34 & -2.49 \\
\hline 7 & 235 & -0.44 & -2.79 \\
\hline 8 & 205 & -0.58 & -3.02 \\
\hline 9 & 175 & -0.52 & -2.83 \\
\hline 10 & 145 & -0.47 & -2.66 \\
\hline 11 & 125 & -0.43 & -2.53 \\
\hline 12 & 95 & -0.38 & -2.39 \\
\hline 13 & 85 & -0.35 & -2.26 \\
\hline 14 & 70 & -0.3 & -2.22 \\
\hline 15 & 50 & -0.26 & -2.12 \\
\hline 16 & 30 & -0.19 & -1.85 \\
\hline 17 & 20 & -0.15 & -1 \\
\hline 18 & 10 & -0.1 & -0.4 \\
\hline 19 & 10 & -0.08 & -0.3 \\
\hline 20 & 20 & -0.09 & -0.3 \\
\hline 21 & 30 & -0.12 & -0.4 \\
\hline 22 & 50 & -0.16 & -0.45 \\
\hline 23 & 70 & -0.18 & -0.55 \\
\hline 24 & 85 & -0.19 & -1.85 \\
\hline
\end{tabular}


Thoth Publishing House

\begin{tabular}{|l|l|l|l|}
\hline \multirow{2}{*}{$\begin{array}{c}\text { Measuring } \\
\text { point* }\end{array}$} & \multicolumn{1}{|c|}{ Distance $[\mathrm{mm}]$} & \multicolumn{2}{c|}{ Value $[\mathrm{mm}]^{* * *}$} \\
\cline { 2 - 4 } & \multicolumn{1}{|c|}{$\mathrm{x}$} & $\mathrm{DW}$ sample** & \multicolumn{1}{c|}{ FW sample** } \\
\hline 25 & 95 & -0.2 & -1.98 \\
\hline 26 & 125 & -0.25 & -2.12 \\
\hline 27 & 145 & -0.31 & -2.28 \\
\hline 28 & 175 & -0.37 & -2.41 \\
\hline 29 & 205 & -0.44 & -2.63 \\
\hline 30 & 235 & -0.38 & -2.48 \\
\hline 31 & 265 & -0.33 & -2.29 \\
\hline 32 & 285 & -0.28 & -2.07 \\
\hline 33 & 315 & -0.23 & -1.8 \\
\hline 34 & 345 & -0.18 & -1.1 \\
\hline 35 & 375 & -0.14 & -0.5 \\
\hline 36 & 400 & -0.08 & -0.3 \\
\hline
\end{tabular}

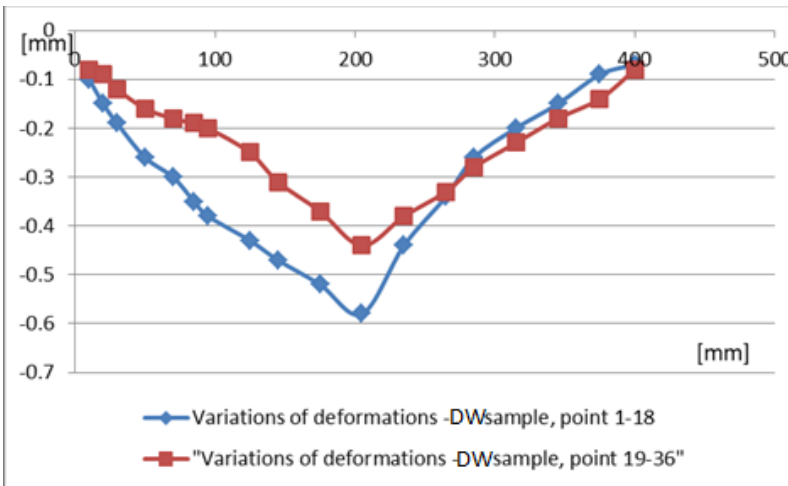

Figure 10. Variation of deformations resulting in welding - sample DW

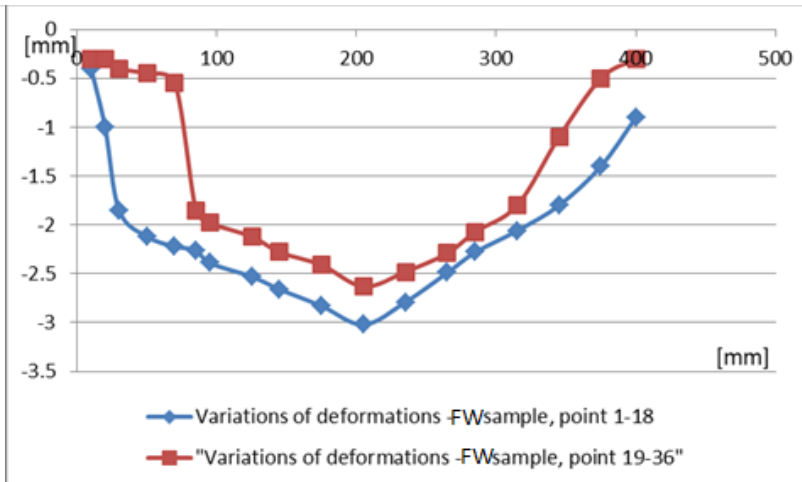

Figure 11. Variation of deformations resulting in welding - sample $\mathrm{FW}$

From the analysis of figure 10, it can be seen that, irrespective of the measurement lines, a and b, the values follow a pattern in the sense that they decrease until the half of the reconditioned sample, and then start to grow. Also, it can be noticed that in the case of points 35-32 the values are lower than in the case of points 14-18, which leads to the idea that the grip in the device was done irregularly. From the analysis of Figure 11., we observe the same tendency as in the previous case with the difference that in this case, since there is no fixing device, the effect of irregular tightening of the sample with the device no longer appears.

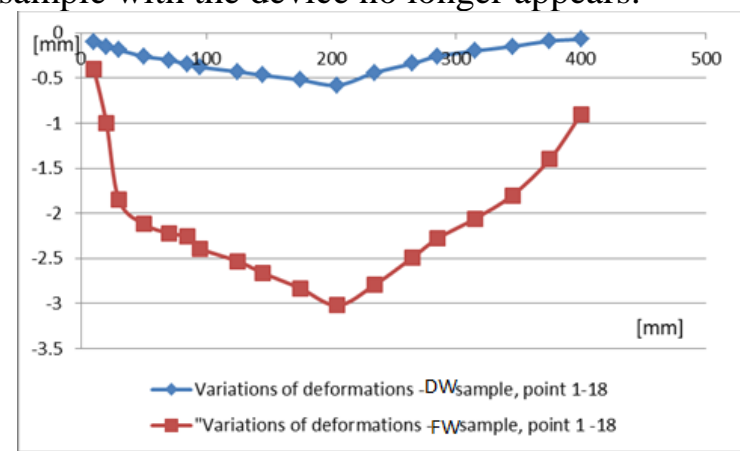

Figure 12. Comparison of deformations values DW and FW samples at measurement points 1-18

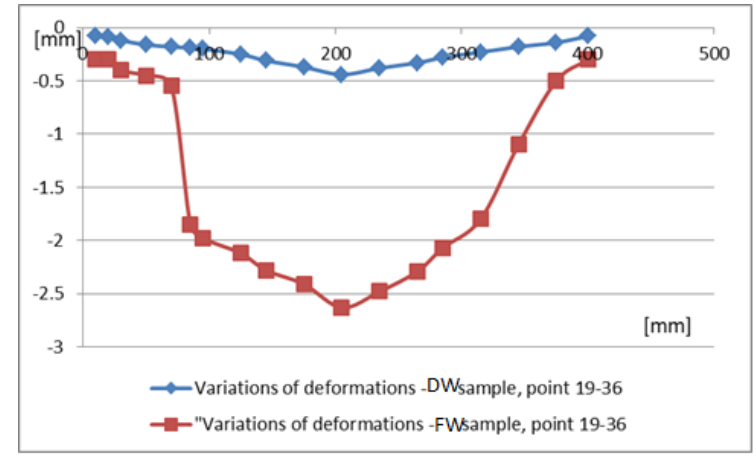

Figura 13. Comparison of deformations values - DW and FW samples at measurement points 19-36 
By comparing the results obtained in the case of the two samples, DW and FW in the measurement points $1-18$, it is observed that the FW piece has deformed quite a lot in the opposite side of the deposit of the cords, Figure 12, a common phenomenon and in the case of comparing the results for points 19-36, Figure 13.

\section{Conclusions}

The following conclusions can be drawn from the research carried out:

- the welding procedure applied, led to the achievement of the pre-set dimensions in the repair technologies;

- from the point of view of analysing the appearance of the welding layers, the samples received the decision "Admitted";

- in the examination with penetrating liquids, non-conformities of the type: pores, cracks, etc., with dimensions larger than the minimum allowable level for which the samples were classified as REJECTED were highlighted;

- following the deformations analysis it was found that in the case of the device welded sample, the level of deformations was minimal (but is needed to pay high attention to the tightening of the piece in the device);

- in the case of the freely welded sample the maximum deformation was recorded in the section plane $\mathrm{H}$ and it was $-3.02 \mathrm{~mm}$;

- the macroscopic analysis revealed that the base material melted a larger quantity in some areas than in other areas, a situation explained by the fact that the welding speed was not constant;

- the results obtained lead to the conclusion that the welding process can be applied as a technological process of restoring the geometric shape.

It is necessary to continue the research in order to establish the process of reconditioning by optimum welding, both from the point of view of the quality of the reconditioned parts and from the economic point of view.

\section{References}

[1] https://www.millerwelds.com/-/media/miller-electric/files/pdf/resources/guidelines smaw.pdf

[2] Simuț V., Stoica M. -Rolling stock braking, ASAB Publishing House, 2014

[3] UIC Code 541-3 OR Brakes -Disc Brakes and their application-General conditions for the approval of brake pads

[4] UIC Code 546 OR Freinsa haute puissance pour trains de voyageurs

[5] Stoica M. - Train braking - Railway edition, Bucharest, 1998

[6] Dumitru G. M., Radu C., Dumitru B. - Reconditioning and repairing products, Printech Publishing House, Bucharest, 2010

[7] Zgură Gh., Ronțescu C., Cicic D.T. - Welding technology through melting, Politehnica Press Publishing, 2007

[8] Solomon Ghe., Cicic D-T., - Theory of welding processes, Theoretical and applicative notions, Welding metallurgy, Bren Bucharest Publishing House, 2010.

[9] https://www.researchgate.net/figure/Types-of-welding-deformation_fig1_43169567

[10] https://link.springer.com/chapter/10.1007/1-4020-2991-8 10

[11] https://www.dijkkamp.nl/en/materials/ggg40-en-gjs-400-15/

[12] EN 1563 : 2012, Founding - Spheroidal Graphite Cast Irons 